\title{
Efficacy and Safety of Basal Analog Regimens in Type 2 Diabetes Mellitus: Systematic Review and Meta- Analysis of Randomized Controlled Trials
}

\author{
Ting Hong · Jing Lu • Pengzi Zhang · Zhou Zhang • Qianyue Xu • \\ Yunguang Li · Nan Cui · Ambar Grijalva · Erin M. Murray • \\ Michael A. del Aguila · Yan Bi
}

Received: February 1, 2019 / Published online: April 6, 2019

(C) The Author(s) 2019

\section{ABSTRACT}

Introduction: This study compared basal analog (BA: glargine U100/mL and detemir) and premix (PM: human, lispro and aspart biphasic) insulin regimens in terms of their efficacy and safety in type 2 diabetes mellitus patients.

Methods: Searches of MEDLINE, Embase, and CENTRAL identified primary randomized controlled trials (RCTs) $\geq 12$ weeks in duration that compared BA or PM insulin regimens in adults with $\mathrm{T} 2 \mathrm{DM}$, with $\geq 30$ patients per arm. A

Ting Hong and Jing Lu should be considered joint first authors.

Enhanced Digital Features To view enhanced digital features for this article go to https://doi.org/10.6084/ m9.figshare.7867997.

Electronic supplementary material The online version of this article (https://doi.org/10.1007/s13300019-0606-6) contains supplementary material, which is available to authorized users.

T. Hong · J. Lu · P. Zhang · Z. Zhang · Q. Xu .

Y. Bi $(\bowtie)$

Department of Endocrinology, Drum

Tower Hospital Affiliated with Nanjing University

Medical School, Nanjing, China

e-mail: biyan@nju.edu.cn

Y. Li · N. Cui

Sanofi (China) Investment Co., Ltd., Shanghai

Branch, China Medical Affairs, Shanghai, China

A. Grijalva - E. M. Murray · M. A. del Aguila

Doctor Evidence, Santa Monica, CA, USA systematic literature review and a pairwise meta-analysis were performed using a random effects model adjusted for between-study variability. Analyses were conducted based on frequency of bolus insulin and PM injections, PM ratio and type, BA type, race, follow-up period, and baseline glycosylated hemoglobin (HbA1c). Results: Twenty-two primary RCTs with 9691 patients were included. The BA and PM regimens yielded similar changes in HbA1c and postprandial glucose levels, with a statistically significant reduction in fasting glucose [mean difference (MD) - $0.61 \mathrm{mmol} / \mathrm{L}(95 \%$ confidence interval (CI) $\left.-0.90,-0.32), I^{2}=89.6 \%\right]$. The BA regimens showed significantly reduced rates of total hypoglycemia [odds ratio (OR) 0.77 (95\% CI 0.64, 0.92), $\left.I^{2}=65.3 \%\right]$ and changes in body weight [MD $-0.48 \mathrm{~kg}(95 \% \mathrm{CI}$ - 0.86, - 0.11), $\left.I^{2}=75.7 \%\right]$ compared to PM regimens. Stratification by PM type and dosing ratio demonstrated statistically significant reductions in $\mathrm{HbA} 1 \mathrm{c}$ favoring $\mathrm{BA}$ compared to human [MD - 0.39\% (95\% CI - 0.60, - 0.18), $I^{2}=61.8 \%$ ] or $50 / 50$-ratio [MD $-0.22 \%(95 \%$ CI $\left.-0.40,-0.04), I^{2}=0.0 \%\right]$ PM regimens. Other subgroup analyses found no difference in HbA1c change between the BA and PM regimens.

Conclusion: When compared to PM regimens, BA regimens yielded similar efficacies and better safety profiles in patients with type 2 diabetes mellitus.

Funding: Sanofi (Shanghai, China). 
Keywords: Basal-bolus insulin therapy; Basal insulin analogues; Meta-analysis; Premix insulin therapy; Systematic review; Type 2 diabetes mellitus

\section{INTRODUCTION}

The World Health Organization estimates that 422 million adults worldwide have type 1 or 2 diabetes, with the majority afflicted with type 2 diabetes mellitus (T2DM) [1]. In OAD-treated T2DM patients with inadequate glucose control defined as glycosylated hemoglobin (HbA1c) $>7 \%$, guidelines support the use of basal insulin as an add-on therapy [2-4]. Basal insulin analogs (BAs), including glargine $(100 \mathrm{U} / \mathrm{mL})$ and detemir, are currently more widely used than traditional neutral protamine Hagedorn (NPH) basal insulin, as BAs provide similar efficacy while reducing the risk of hypoglycemia [5]. Insulin intensification involving the combination of a BA with prandial insulin injection, also known as a basal-plus or basal-bolus (BB) regimen, is prescribed if no improvements are observed in patients treated with adequate BA [4]. Premix (PM) insulin is another common insulin prescribed worldwide, with recommendations varying by geographic location. PM insulin consists of rapid and NPH insulin components given in different ratios; this eliminates the need for patients to mix the insulin themselves while also reducing the number of injections required each day [6].

Several studies have attempted to determine whether BA or PM insulin is more efficacious in the treatment of T2DM, but results have varied significantly by study. A systematic literature review comparing insulin analogs demonstrated that more patients achieved a clinically relevant HbA1c level with biphasic or prandial insulin when compared to BA [7]. A larger systematic literature review consisting of 55 randomized controlled trials (RCTs) revealed that a higher proportion of patients achieved HbA1c $<7 \%$ $(51.2 \%)$ when treated with BB regimens compared to those treated with biphasic or prandial insulin [8]. A recent systematic literature review (2016) and pairwise meta-analysis demonstrated that there was no clinically relevant difference in the HbA1c reductions achieved with BB and PM insulin [9]. Furthermore, these systematic literature reviews did not compare the full treatment journeys of patients on BA insulin regimens (from BA insulin plus OADs to a $\mathrm{BB}$ regimen) and those on $\mathrm{PM}$ insulin regimens (from PM insulin twice daily (BID) to thrice daily (TID)). Therefore, we performed a systematic literature review and pairwise metaanalysis to determine which treatment was superior and more beneficial for patients.

\section{METHODS}

\section{Search Strategies and Database}

A comprehensive literature search of MEDLINE, Embase, and the Cochrane Central Register of Control Trials (CENTRAL) was conducted, covering the period from January 1, 1997 to October 31, 2017. A standardized review protocol was used to define the eligibility criteria applied when searching for and screening references, guided by the population, intervention, comparator, outcome, timing, setting, and study design [PICO(TSS)] framework (Table S1 in the Electronic supplementary material, ESM) [10]. Inclusion criteria included primary RCTs with adult T2DM patients, an intervention group who received a BA (insulin glargine or detemir), a comparator group who received a PM insulin, a minimum follow-up period of 12 weeks, and a minimum of 30 patients per treatment arm. The studies also needed to report data on at least one efficacy outcome (HbA1c, fasting glucose, 2-h postprandial glucose, and total insulin dose) or safety outcome (body weight and hypoglycemia). Keywords used in the search strategy included type 2 diabetes, basal insulin, glargine, detemir, premix, biphasic insulin AND 50/50, $75 / 25,70 / 30$. The search strategy employed for each of these databases is described in more detail in Table S2a-c of the ESM. The present article is based on previously conducted studies and does not contain any studies with human participants or animals performed by any of the authors. 


\section{Study Selection}

Study selection and screening were conducted using the web-based platform Digital Outcome Conversion (DOC) Library (version 2.0; Doctor Evidence, LLC, Santa Monica, CA, USA), according to a screening protocol based on the PICO(TSS) criteria. An assessment of the quality of the included studies was conducted by two reviewers using the Cochrane Collaborations tool for assessing the risk of bias in randomized trials [11]. This instrument is used to evaluate seven domains of bias: random sequence generation (selection bias), allocation concealment (selection bias), blinding of participants and personnel (performance bias), blinding of outcome assessment (detection bias), incomplete outcome data (attrition bias), selective reporting (reporting bias), and other sources of bias (other bias). Data were stored and managed in Microsoft Excel. Discrepancies were resolved by an independent reviewer.

\section{Outcome Collection}

Data extraction was conducted using the DOC Data version 2.0 software platform (Doctor Evidence) and its universal electronic extraction form, based on a standardized data configuration protocol. Continuous outcomes included change from baseline (reported or calculated) in HbA1c, fasting glucose, 2 -h postprandial glucose, and body weight. Data on total insulin dose at the end of follow-up were also collected. Change from baseline was calculated for selected outcomes when the study did not report this data. This was possible if the outcome was reported at the endpoint and baseline. The change was calculated by subtracting the baseline value from the endpoint value. The standard deviation (SD) in the outcome change, assuming a correlation of 0.8, was calculated based on Eq. (1) in the Cochrane Handbook [10]:
Fasting glucose and postprandial glucose data extracted included both plasma and capillary glucose values. Postprandial glucose measurements obtained $2 \mathrm{~h}$ after breakfast (or, for one study, after lunch) were included. In the total insulin dose analysis, a unit conversion of $\mathrm{U}$ or IU to $\mathrm{U} / \mathrm{kg}$ to adjust for patient body weight was performed for analytical purposes. Categorical outcomes included the proportion of patients achieving HbA1c levels $<7 \%$ or $\leq 7 \%$ and total hypoglycemia by the end of follow-up. The latter was evaluated based on the author's definition and included symptomatic and asymptomatic events, measured glucose events, and self-diagnosed events. Primary efficacy outcomes were change from baseline in HbA1c and HbA1c levels $<7 \%$ or $\leq 7 \%$. Secondary efficacy outcomes were fasting glucose, total insulin dose at the end of the study, and 2-h postprandial glucose.

\section{Statistical Methods}

A pairwise meta-analysis (MA) was performed for the outcomes of interest (i.e., HbA1c, fasting glucose, 2-h postprandial glucose, total insulin dose, body weight, and hypoglycemia). The conventional DerSimonian-Laird random-effects model was utilized. We calculated heterogeneity across studies using the Cochran $Q$ test and the $I^{2}$ statistic. $I^{2}>50 \%$ indicated significant heterogeneity [10]. All analyses were done in R 3.5.2 using the "metafor" package [12]. The comparative efficacy for each outcome was represented by the odds ratio (OR) and the associated $95 \%$ confidence interval (CI) for categorical data, or the mean difference (MD) and the associated 95\% CI for continuous data. The original comparison was stratified by BA and PM insulin frequencies, including BA once daily (QD) with or without $( \pm)$ OAD vs. PM insulin BID \pm OAD (9 studies: [13-21]), basalbolus insulin given once a day (BB insulin $1 \times$ )

$$
\text { SD change }=\sqrt{\text { SD2 baseline }+ \text { SD2 final }-(2 \times \text { Corr } \times \text { SD baseline } \times \text { SD final })} \text {. }
$$


vs. PM insulin BID (3 studies: [2, 22, 23]), basalbolus insulin given thrice a day (BB insulin $3 \times$ ) vs. PM insulin BID (2 studies: $[24,25]$ ), BB insulin $3 \times$ vs. PM insulin TID (2 studies: $[26,27])$, and basal-bolus insulin given zero to thrice daily [BB insulin stepwise $(0-3 \times)]$ vs. PM insulin given zero to twice a day [PM insulin stepwise $(0-2 \times)$ ] (6 studies: [28-33]). These original treatment comparisons are reported in Table 1. Exploratory analyses were conducted for comparisons based on PM insulin type, PM insulin ratio, BA insulin type, race, study followup period, and baseline HbA1c. The studies included in each of these secondary analysis comparisons are summarized in Table S3 of the ESM.

\section{RESULTS}

\section{Search Results}

The search of relevant databases identified a total of 251 studies. Following title and abstract screening, a total of 213 studies were excluded for not aligning with the prespecified PICO(TSS) criteria. Thirty-eight references were full-text screened, of which 16 did not fit the prespecified criteria for intervention (BA insulin), outcomes (change in HbA1c, fasting glucose, 2-h postprandial glucose, and body weight, insulin dose, hypoglycemia), outcome stratification (data not reported for intervention or comparator), study design (RCTs, phase 2-4), or number of participants ( $\geq 30$ patients per arm), and were therefore excluded. The remaining 22 studies met the PICO(TSS) criteria and were considered for data configuration and included in the meta-analysis [2, 13-33]. A PRISMA flowchart of the study selection process is presented in Fig. 1.

\section{Study Characteristics}

A summary of study characteristics is provided in Table 1. A total of 9691 patients were included in the analysis. The most common BA insulin treatments were insulin glargine 100 U/mL (19 studies: [2, 13-15, 17-24, 26-32]) and insulin aspart (11 studies: [15, 16, 18-20,
$22,23,25,31-33])$. The patient characteristics in each trial are also reported in Table 1. Fasting plasma glucose ranged from a mean of $5.8 \mathrm{mmol} / \mathrm{L}(105.1 \mathrm{mg} / \mathrm{dL})$ in insulin glargine $100 \mathrm{U} / \mathrm{mL}+$ glulisine $0-2 \times$-treated patients [31] to $14 \mathrm{mmol} / \mathrm{L}(252 \mathrm{mg} / \mathrm{dL})$ in insulin aspart BID + OAD-treated patients [20]. HbA1c levels ranged from a mean of $8.07 \%$ in patients who received insulin glargine $100 \mathrm{U} / \mathrm{mL}+$ sitagliptin [15] to $11.4 \%$ in patients who received insulin glargine $100 \mathrm{U} / \mathrm{mL}+$ metformin + sulfonylurea [13].

\section{Quality Assessment}

Table S2d in the ESM presents a summary of the quality of the 22 studies. There was generally a low risk of selection bias across the studies, with some studies judged as having an unclear risk of such bias. In eight studies $[13,16,18$, $20,25,28,32,33]$, inadequate methods of generating the randomization sequence were reported; similarly, seven studies were judged to have an unclear risk of allocation concealment due to insufficient details $[2,13,15,16,28$, $32,33]$. Risk of performance bias (pertaining to the blinding of participants and personnel) and risk of detection bias (pertaining to blinding of outcome assessment) were primarily judged to be high, as most of the studies had an openlabel study design. All of the studies had a low risk of attrition and reporting bias. Finally, nearly all the studies had a low risk of other sources of bias.

\section{Primary Efficacy Outcomes (HbA1c)}

The primary efficacy outcome of mean change from baseline in HbA1c was reported or calculated in all 22 trials and included in the analysis [2, 13-33]. The MD values for the overall comparisons and for each of the five primary analysis comparisons are reported in Fig. 2a. There was no statistically significant difference in HbA1c change from baseline between patients who used BA regimens and patients who used PM insulin [- 0.04\% (95\% CI - 0.14, 0.07)], with significant heterogeneity of effect size across the included trails $\left(I^{2}=77.4 \%\right.$, 


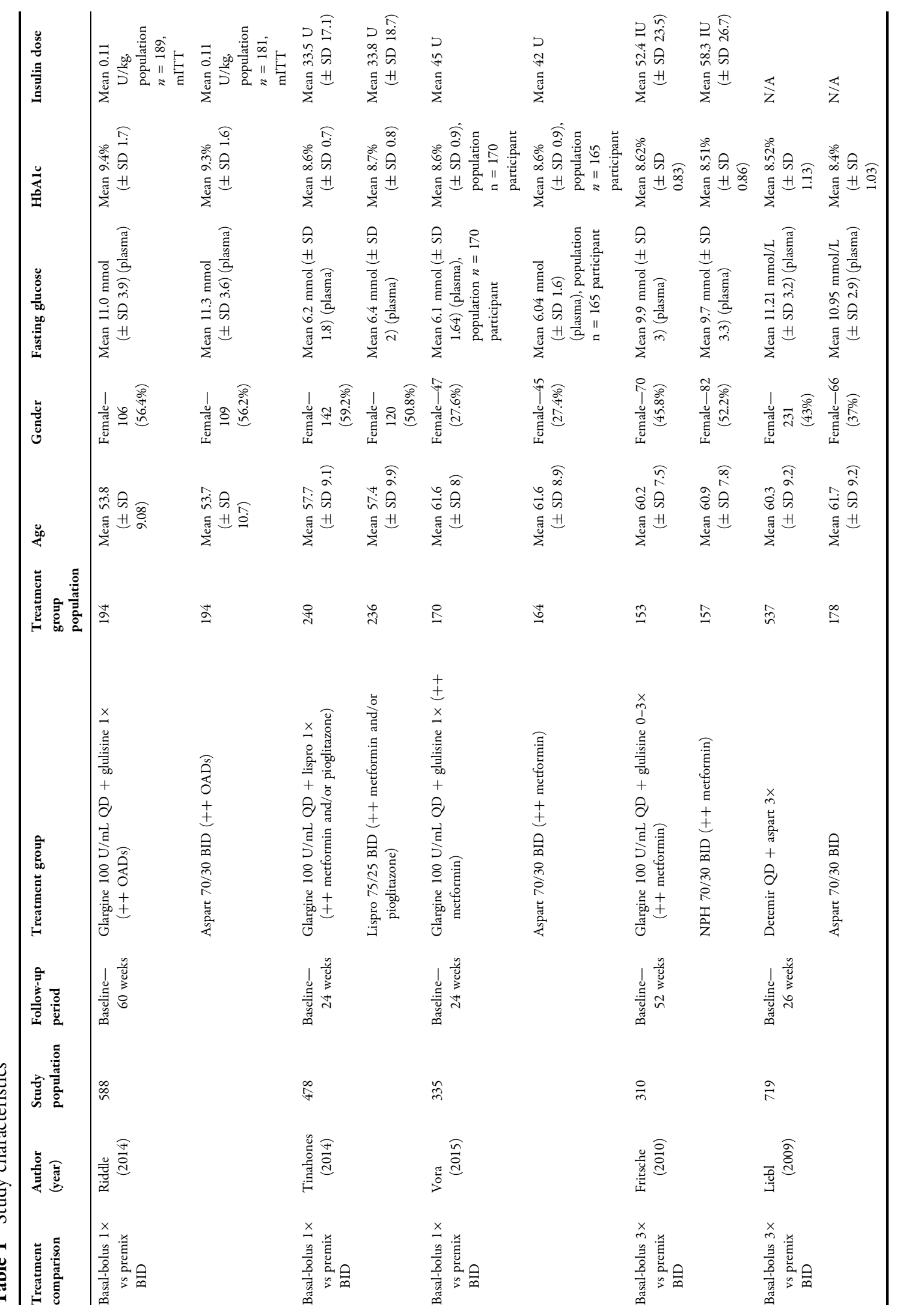




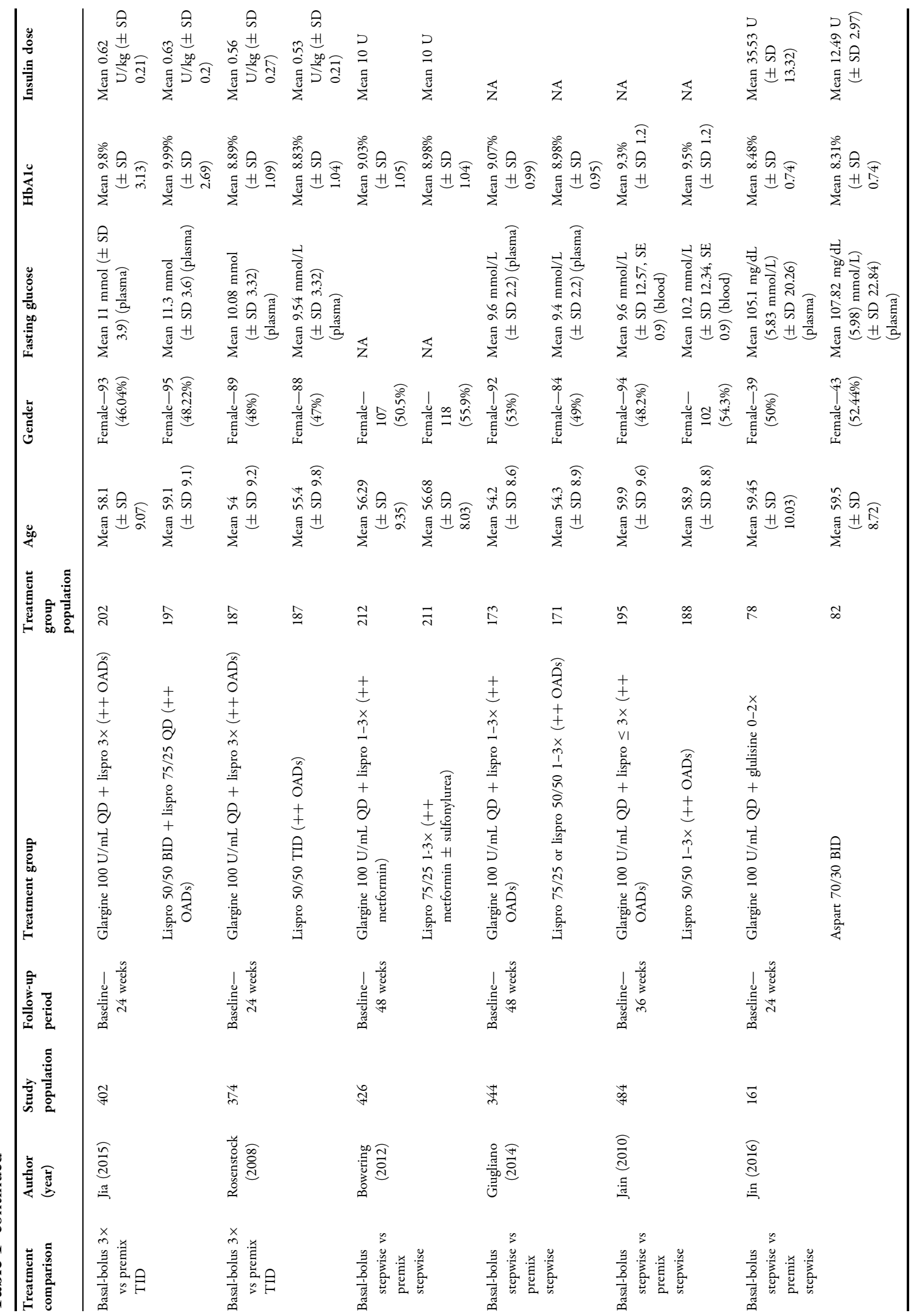




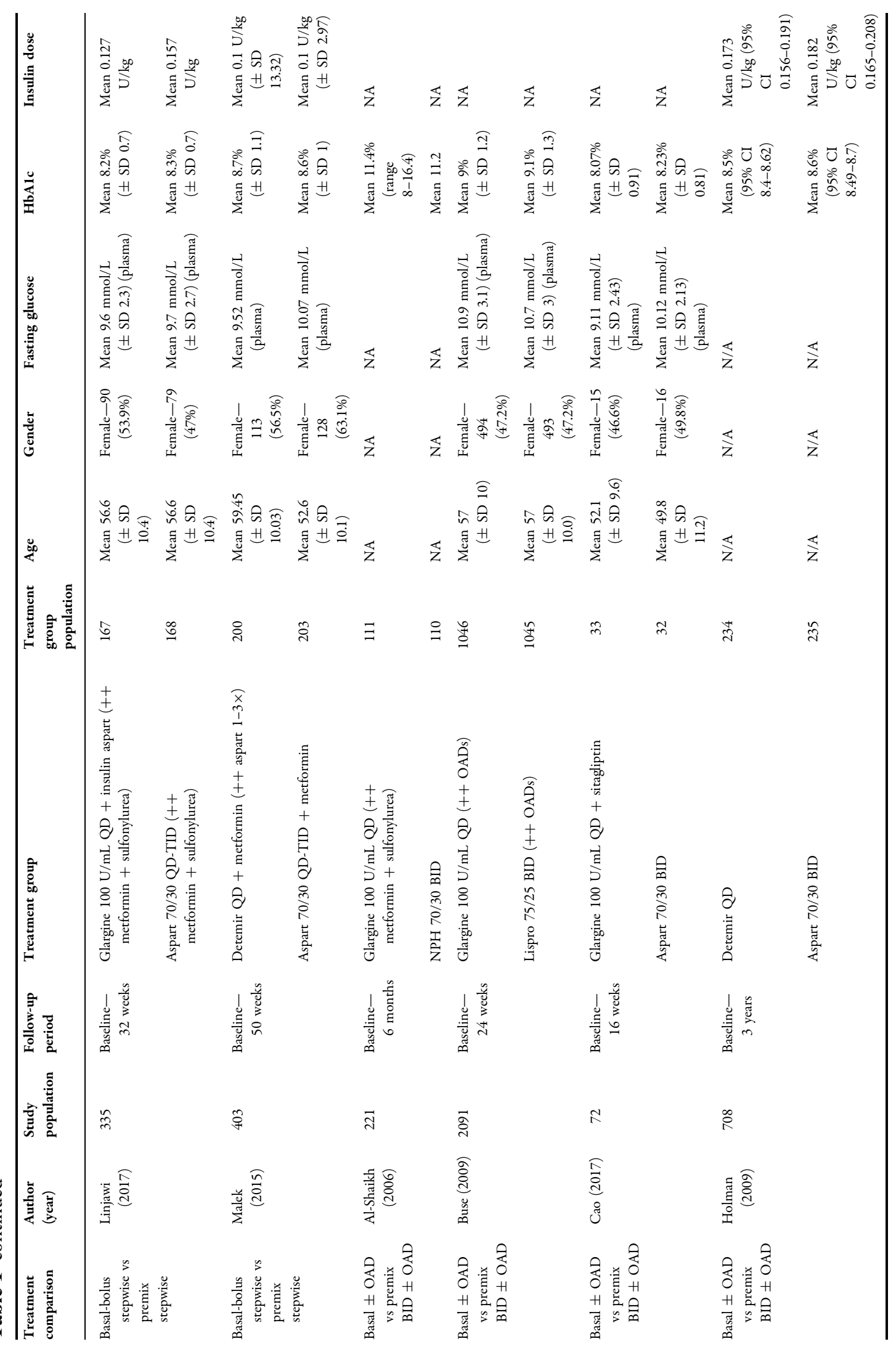




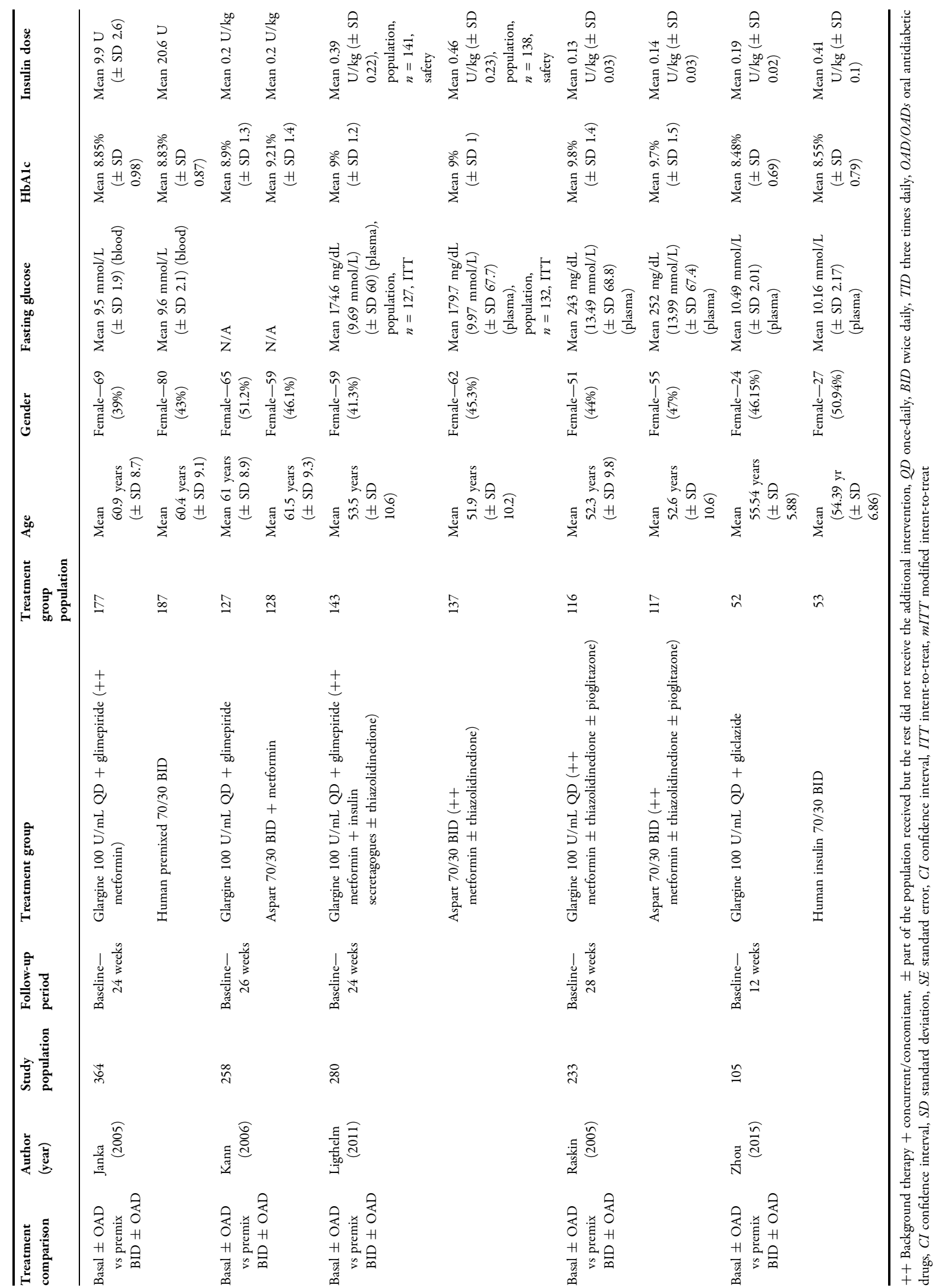




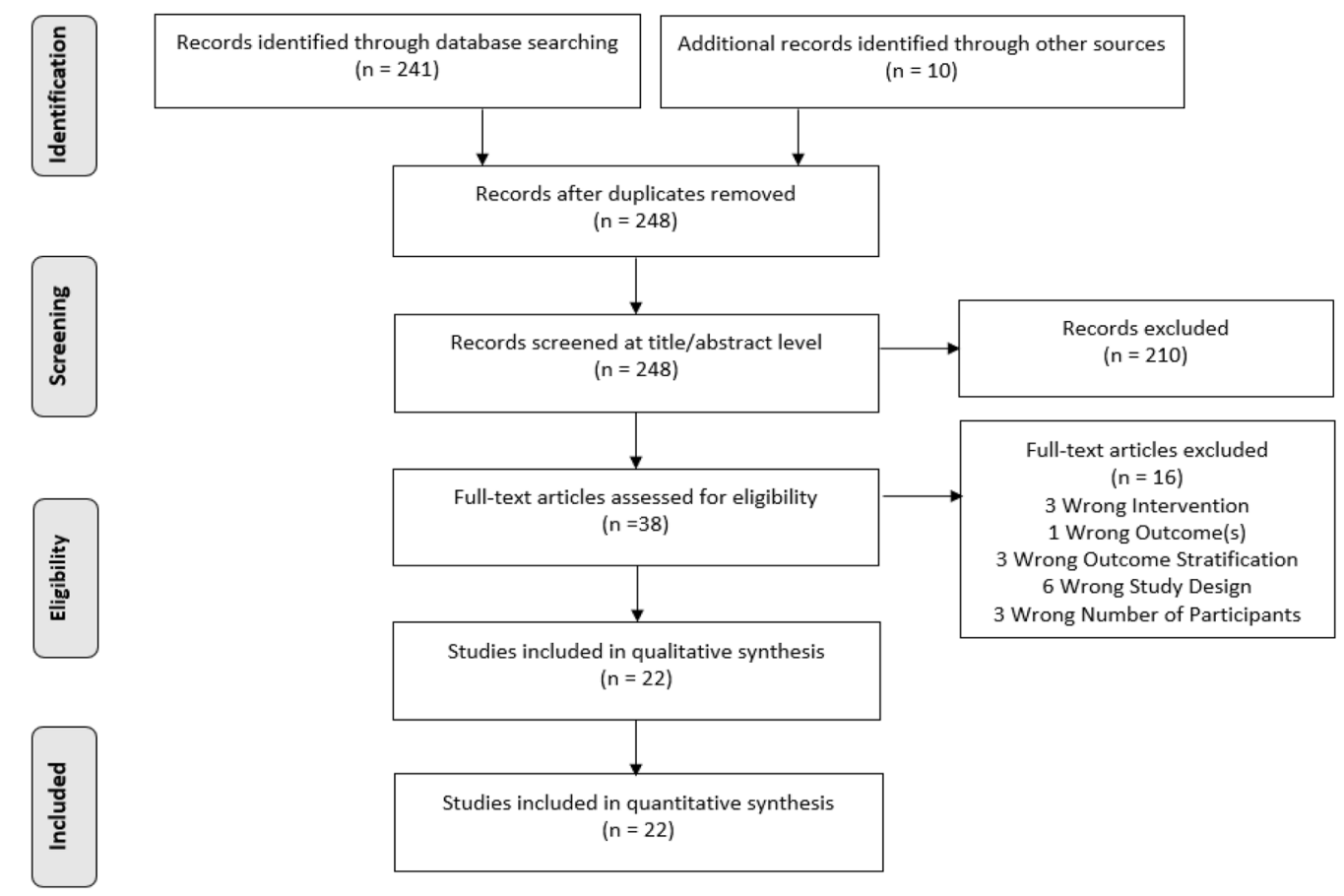

Fig. 1 PRISMA flow diagram for the study selection process

$p$ value $<0.05$ ) (Fig. 2 a). A comparison of $\mathrm{BB}$ insulin $3 \times$ to PM insulin BID highlighted a statistically significant difference in $\mathrm{HbA1c}$ reduction [- 0.37\% (95\% CI - 0.64, - 0.10)] (Fig. 2a). In contrast, BA therapy \pm OAD led to a similar HbA1c change to that achieved with PM insulin in combination or without OAD [0.00\% $(95 \%$ CI $-0.21,0.20)]$, suggesting that the change observed in the $\mathrm{BB}$ insulin $3 \times$ group resulted from the bolus injections (Fig. 2a). Exploratory analyses were conducted for comparisons based on BA or PM insulin types and patient/trial characteristics, as further summarized in Table S3 of the ESM. When examining PM insulin stratified by type, there was a statistically significant difference in HbA1c reduction between patients on BA insulin regimens and those receiving regular human PM insulin [- 0.39\% (95\% CI - 0.60, - 0.18)] (Table S4 in the ESM). A secondary analysis of PM insulin ratio also revealed a statistically significant difference in the change in HbA1c between those receiving BA insulin regimens and those receiving PM 50/50 insulin [- 0.22\% (95\% CI $-0.40,-0.04)]$ (Table S4 in the ESM). None of the other secondary analysis comparisons showed statistically significant differences in change from baseline HbA1c (Table S4 in the ESM).

HbA1c $\leq 7 \%$ was reported and analyzed in all 22 trials [2, 13-33]. ORs for the overall comparisons and for each of the five primary analysis comparisons are reported in Fig. 2b. Overall, although there were no statistically significant differences between patients who used BA insulin regimens and those who used PM insulin $[1.14$ (95\% CI 0.94, 1.40)], there was significant heterogeneity of effect size across the included trials $\left(I^{2}=78.7 \%, p\right.$ value $\left.<0.05\right)$ (Fig. 2b). The odds of achieving HbA1c $\leq 7 \%$ were highest with $\mathrm{BB}$ insulin $3 \times$ compared to $\mathrm{PM}$ insulin BID [1.76 (95\% CI 1.17, 2.64)] (Fig. 2b).

\section{Secondary Efficacy Outcomes (Fasting Glucose, 2-h Postprandial Glucose, and Insulin Dose)}

Change from baseline in fasting glucose was an average of $0.61 \mathrm{mmol} / \mathrm{L}$ smaller in patients who used BA than in patients who used PM insulin regimens $[-0.61 \mathrm{mmol} / \mathrm{L}$ (95\% CI - 0.90, - 0.32)] (Table 2). Three primary analyses showed statistically significant differences, 
A

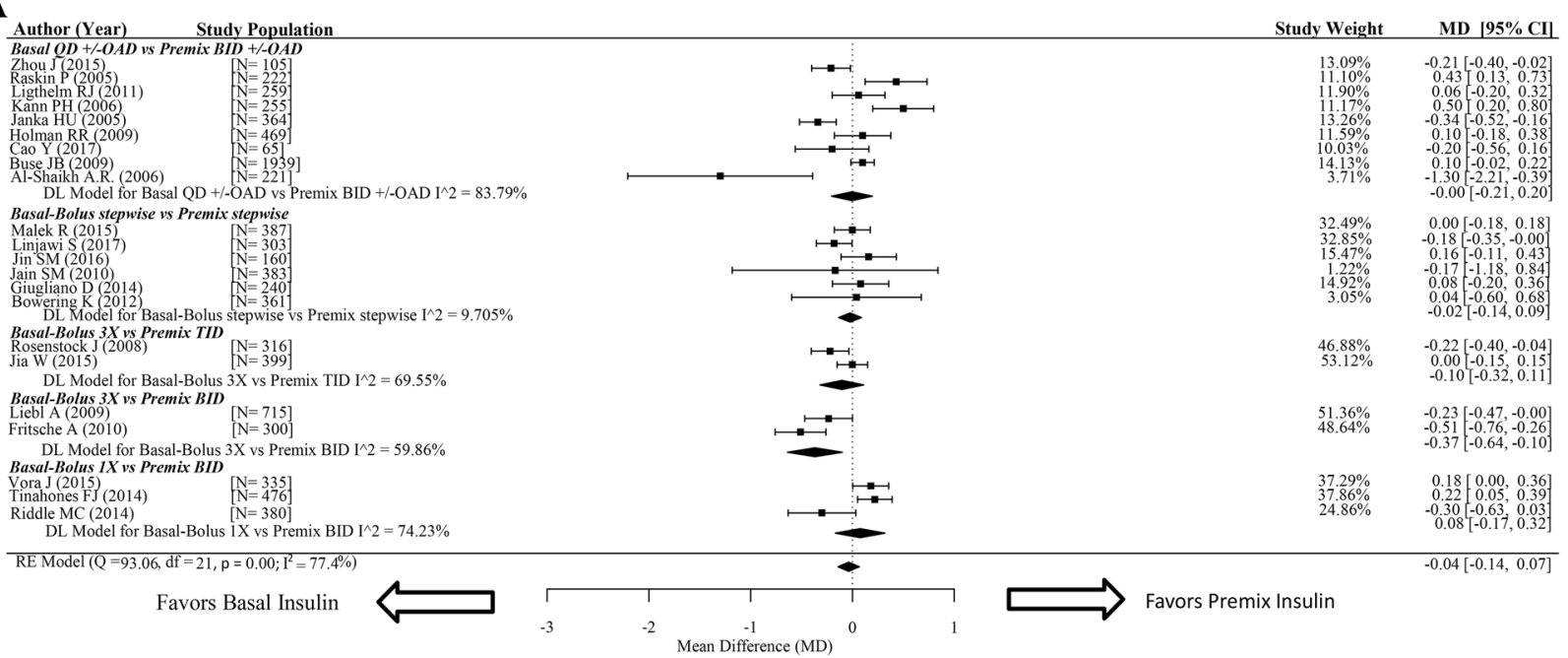

B

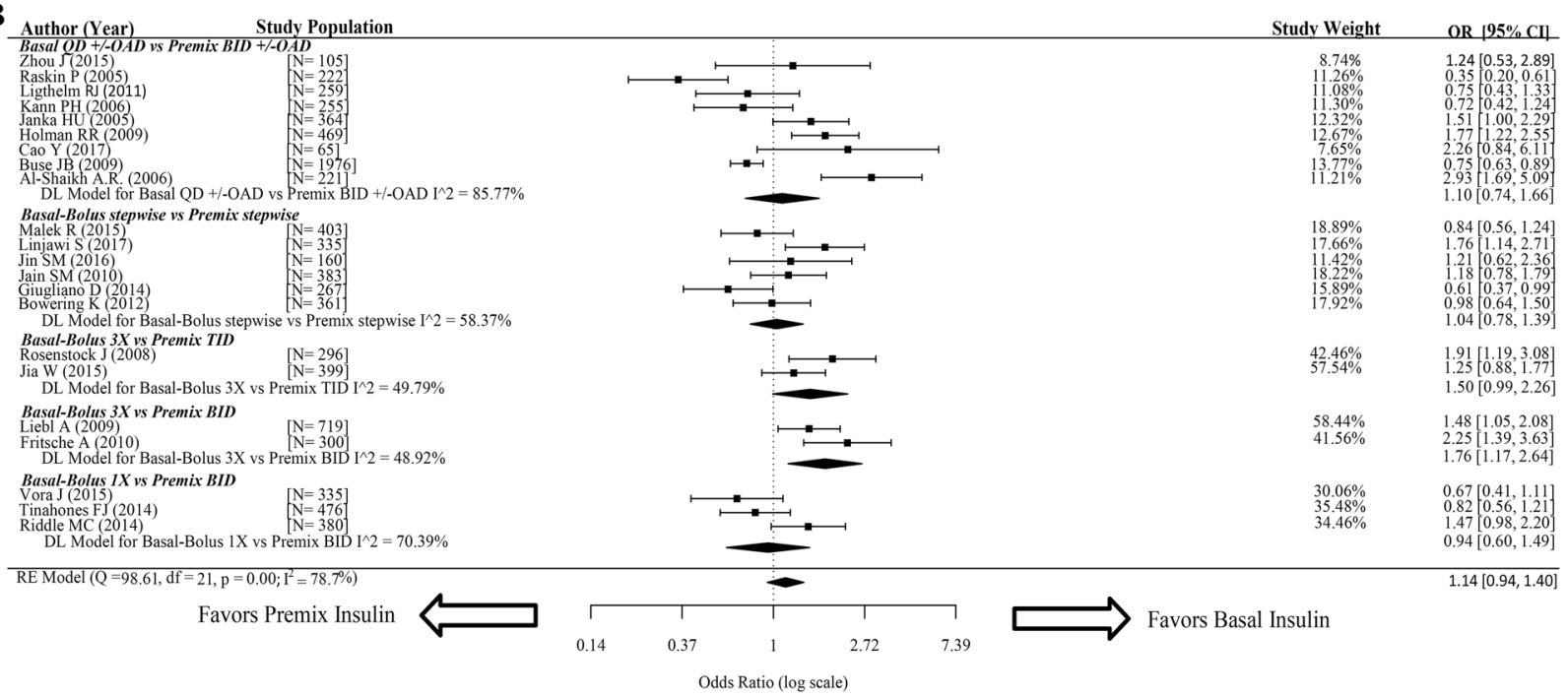

Fig. 2 Efficacy analysis for primary comparisons. The figure depicts Forest plots for pairwise meta-analysis of efficacy outcomes for a change from baseline HbAlc and b HbAlc $<7 \%$. The $I^{2}$ value was used to assess heterogeneity. Results are shown as the mean difference (MD) for continuous data along with the associated $95 \%$

including BB insulin stepwise versus PM insulin

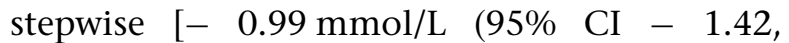
$-0.55)$, BB insulin $3 \times$ versus PM insulin TID $[-0.74 \mathrm{mmol} / \mathrm{L}(95 \% \mathrm{CI}-1.46,-0.02)]$, and BA insulin $\mathrm{QD} \pm \mathrm{OAD}$ versus $\mathrm{PM}$ insulin $\mathrm{BID} \pm$ OAD [- $0.59 \mathrm{mmol} / \mathrm{L}, 95 \% \mathrm{CI}-1.06,-0.12)]$ (Table 2).

Although not statistically significant, the evidence suggests that total insulin dose was on average $0.06 \mathrm{U} / \mathrm{kg}$ lower in patients who used
CI for change from baseline HbAlc, and the odds ratio (OR) along with the associated $95 \%$ confidence interval (CI) for HbAlc $<7 \%$. $Q D$ once daily, $B I D$ twice daily, $T I D$ three times daily, $O A D / O A D s$ oral antidiabetic drugs, $M D$ mean difference, $O R$ odds ratio, $C I$ confidence interval

BA compared to those who used PM insulin [- $0.06 \mathrm{U} / \mathrm{kg}(95 \% \mathrm{CI}-0.13,0.01)]$ (Table 2). A significant decrease in total insulin dose was reported for the $\mathrm{BA}$ insulin $\mathrm{QD} \pm \mathrm{OAD}$ patients compared to the $\mathrm{PM}$ insulin $\mathrm{BID} \pm \mathrm{OAD}$ patients $[-0.107 \mathrm{U} / \mathrm{kg}(95 \% \mathrm{CI}-0.32,-0.01)]$ (Table 2).

An increase from baseline in 2-h postprandial glucose was observed in patients who used $\mathrm{BA}$ insulin regimens compared to patients who 
Table 2 Secondary efficacy outcomes: analyses of change from baseline in fasting glucose, change from baseline in 2-h postprandial glucose, and total insulin dose at end of follow-up

\begin{tabular}{|c|c|c|c|c|c|}
\hline \multirow[t]{2}{*}{ Mean difference (MD) } & \multirow[t]{2}{*}{ Number of studies } & \multirow[t]{2}{*}{$I^{2}(\%)$} & \multirow[t]{2}{*}{ Estimate } & \multicolumn{2}{|l|}{$95 \% \mathrm{CI}$} \\
\hline & & & & Lower & Upper \\
\hline \multicolumn{6}{|l|}{ Fasting glucose $(\mathrm{mmol} / \mathrm{L})$} \\
\hline Overall & 16 & 89.6 & -0.61 & -0.90 & $-0.32^{*}$ \\
\hline Basal $\mathrm{QD} \pm \mathrm{OAD}$ vs premix $\mathrm{BID} \pm \mathrm{OAD}$ & 7 & 83.0 & -0.59 & -1.06 & $-0.12^{*}$ \\
\hline Basal-bolus stepwise vs premix stepwise & 3 & 50.8 & -0.99 & -1.42 & $-0.55^{*}$ \\
\hline Basal-bolus $3 \times$ vs premix TID & 2 & 85.5 & -0.74 & -1.46 & $-0.02^{*}$ \\
\hline Basal-bolus $3 \times$ vs premix BID & 2 & 78.4 & -0.24 & -1.22 & 0.75 \\
\hline Basal-bolus $1 \times$ vs premix BID & 2 & 66.9 & -0.51 & -1.35 & 0.32 \\
\hline Overall & 17 & 94.2 & -0.06 & -0.13 & 0.01 \\
\hline \multicolumn{6}{|l|}{ Total insulin dose $(\mathrm{U} / \mathrm{kg})$} \\
\hline Basal $\mathrm{QD} \pm \mathrm{OAD}$ vs premix $\mathrm{BID} \pm \mathrm{OAD}$ & 6 & 97.1 & -0.17 & -0.32 & $-0.01^{*}$ \\
\hline Basal-bolus stepwise vs premix stepwise & 5 & 0.0 & 0.00 & -0.04 & 0.05 \\
\hline Basal-bolus $3 \times$ vs premix TID & 2 & 86.63 & 0.10 & -0.08 & 0.27 \\
\hline Basal-bolus $3 \times$ vs premix BID & 1 & 0.0 & 0.05 & -0.07 & 0.17 \\
\hline Basal-bolus $1 \times$ vs premix BID & 3 & 83.2 & -0.07 & -0.17 & 0.04 \\
\hline Overall & 12 & 90.6 & 0.09 & -0.31 & 0.49 \\
\hline \multicolumn{6}{|l|}{ 2-h postprandial glucose $(\mathrm{mmol} / \mathrm{L})$} \\
\hline Basal $\mathrm{QD} \pm \mathrm{OAD}$ vs premix $\mathrm{BID} \pm \mathrm{OAD}$ & 4 & 81.6 & 0.44 & -0.11 & 0.99 \\
\hline Basal-bolus stepwise vs premix stepwise & 4 & 87.5 & 0.08 & -0.83 & 1.00 \\
\hline Basal-bolus $3 \times$ vs premix TID & 2 & 97.8 & -0.53 & -2.57 & 1.51 \\
\hline Basal-bolus $3 \times$ vs premix BID & 1 & 0.0 & -0.60 & -1.20 & 0.00 \\
\hline Basal-bolus $1 \times$ vs premix BID & 1 & 0.0 & 0.54 & 0.09 & 0.99 \\
\hline
\end{tabular}

$Q D$ once daily, $B I D$ twice daily, $T I D$ three times daily, $O A D / O A D s$ oral antidiabetic drugs, $M D$ mean difference, $C I$ confidence interval

${ }^{*} p$ value $<0.05$

used PM insulin, but this was not statistically significant $[0.09 \mathrm{mmol} / \mathrm{L}(95 \% \mathrm{CI}-0.31,0.49)]$ (Table 2).

\section{Safety Outcomes (Hypoglycemia and Body Weight)}

Total hypoglycemia was suitable for analysis in 19 trials [2, 14-27, 29-31, 33]. Results for overall comparisons and each of the five primary analysis comparisons are reported in Fig. 3a. Patients who used BA insulin regimens had a statistically significantly reduced likelihood of total hypoglycemia compared to those who used PM insulin regimens [0.77 (95\% CI 0.64, 0.92)], with significant heterogeneity of effect size across the included trials $\left(I^{2}=65.3 \%\right.$, $p$ value $<0.05$ ) (Fig. 3a). The only statistically significant difference in hypoglycemia 
A

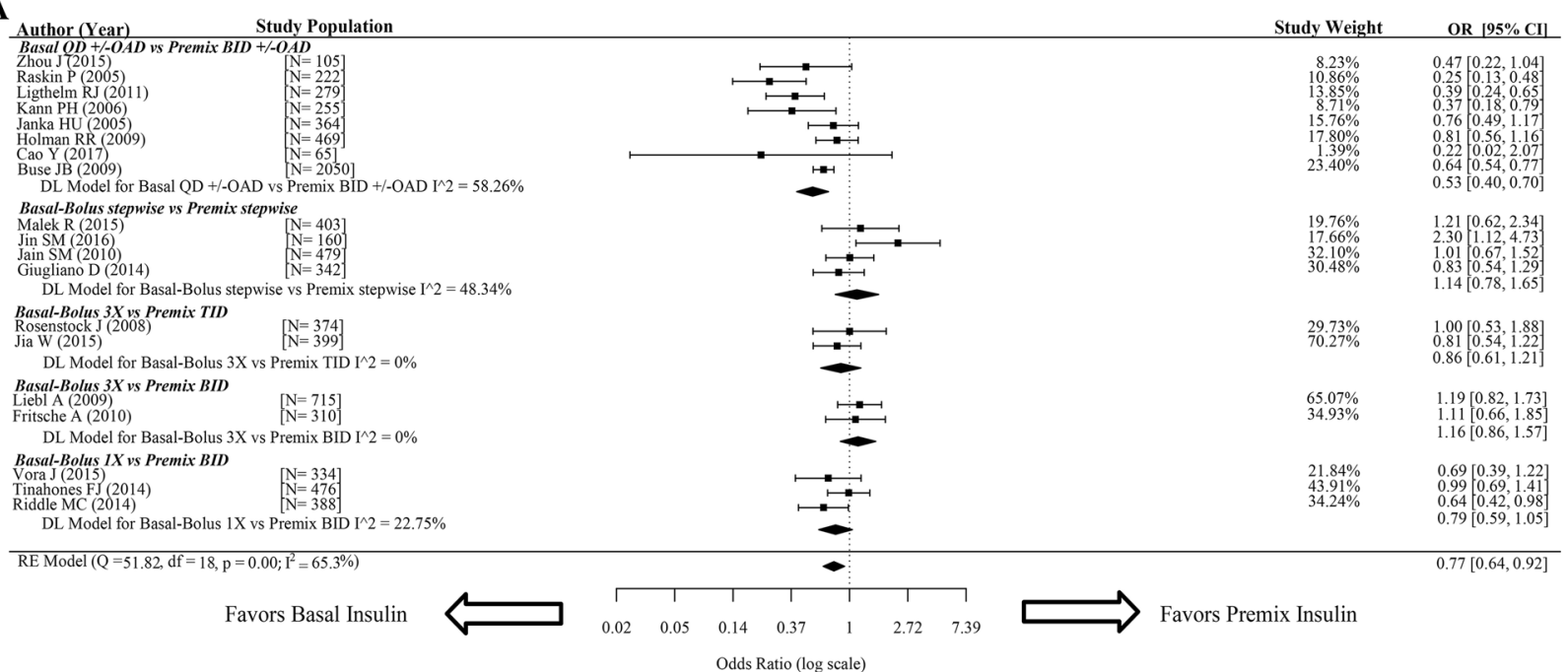

B

B Author (Year)

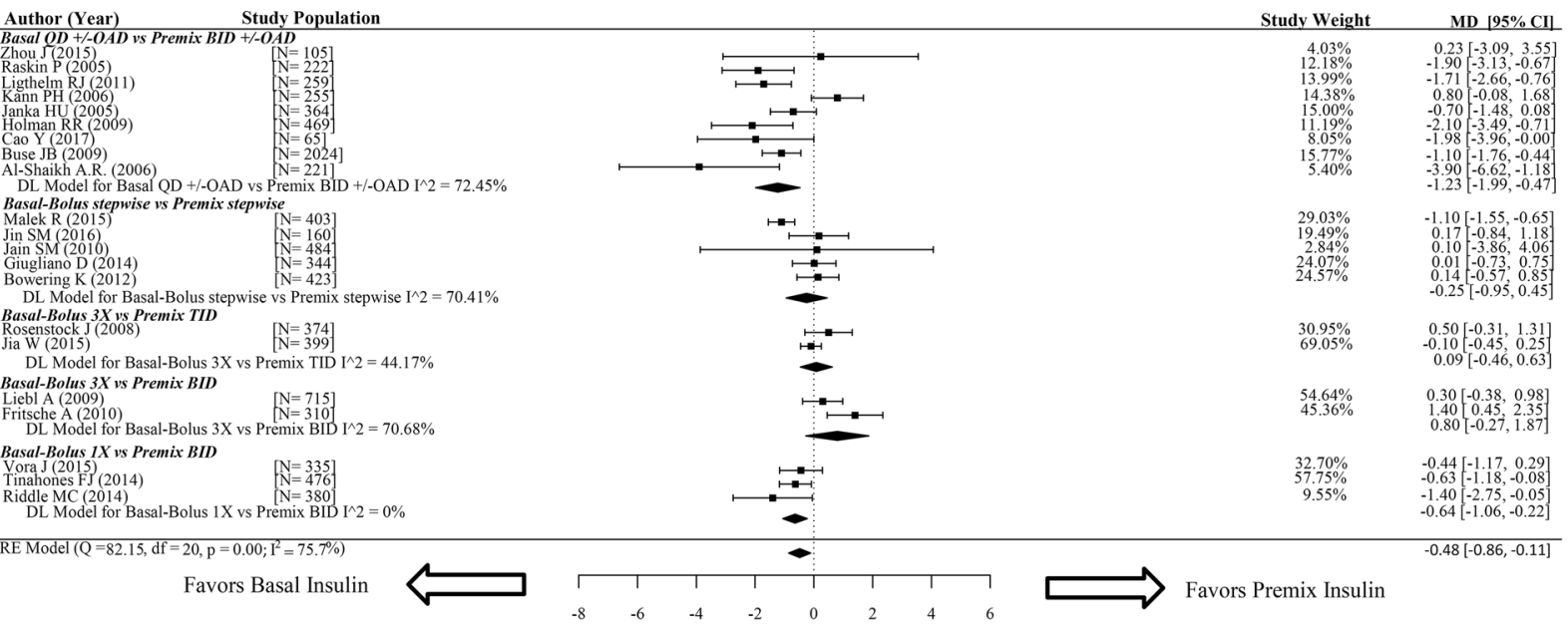

Mean Difference

Fig. 3 Safety, primary analyses. The figure depicts Forest plots for pairwise meta-analysis of safety outcomes for a total hypoglycemia and $\mathbf{b}$ change from baseline in body weight. The $I^{2}$ value was used to assess heterogeneity. Results are shown as the mean difference (MD) for continuous data along with the associated 95\% CI for

incidence in a primary comparison was between the $\mathrm{BA}$ insulin $\mathrm{QD} \pm \mathrm{OAD}$ and $\mathrm{PM}$ insulin $\mathrm{BID} \pm$ OAD groups [0.53 (95\% CI 0.40, 0.70)] (Fig. 3a). Other primary comparisons showed no statistical significant difference in hypoglycemia incidence (Fig. 3a). The results of exploratory analyses of total hypoglycemia for comparisons based on BA or PM insulin types and patient/trial characteristics are summarized in Table S5 in the ESM. body weight, and the odds ratio (OR) with the associated 95\% confidence interval (CI) for total hypoglycemia. $Q D$ once daily, $B I D$ twice daily, TID three times daily, $O A D / O A D s$ oral antidiabetic drugs, $M D$ mean difference, $C I$ confidence interval

Mean change from baseline in body weight was suitable for analysis in 21 trials [2, 13-31, 33], with MDs for overall comparisons and each of the five primary analysis comparisons reported in Fig. 3b. There was a statistically significant difference in body weight between patients who used BA insulin regimens and patients who used PM insulin $[-0.48 \mathrm{~kg}(95 \% \mathrm{CI}-0.86,-0.11)]$, with significant heterogeneity of effect size across the 
included trials $\left(I^{2}=75.7 \%, p \quad\right.$ value $\left.<0.05\right)$ (Fig. 3b). The comparison of the $\mathrm{BA} Q \mathrm{QD} \pm \mathrm{OAD}$ and $\mathrm{PM}$ insulin $\mathrm{BID} \pm \mathrm{OAD}$ groups showed $\mathrm{a}$ significant difference in body weight change [- $1.23 \mathrm{~kg}$ (95\% CI - 1.99, - 0.47)] (Fig. 3b). Body weight change was also significantly different for BB insulin $1 \times$-treated patients and PM insulin BID-treated patients [- $0.64 \mathrm{~kg}(95 \% \mathrm{CI}$ $-1.06,-0.22)$ ] (Fig. 3b).

\section{DISCUSSION}

To the authors' best knowledge, this is the sole systematic literature review and pairwise metaanalysis from the last 5 years that compares BA and PM insulin regimens in terms of relative efficacy and safety. The evidence demonstrated a significant improvement in the efficacy outcome change from baseline in fasting glucose as well as reductions in the safety outcomes change from baseline in body weight and total hypoglycemia likelihood for BA insulin compared to PM insulin. A systematic literature review and pairwise meta-analysis demonstrated that a BA insulin regimen is the optimal choice for patients with type 2 diabetes.

To determine which specific BA or PM insulin regimen is most favorable, primary analyses were conducted based on the original frequencies of BA and PM insulin. When comparing different initial insulin regimes, BA insulin \pm OAD therapy was observed to yield the most statistically significant improvements in both efficacy and safety outcomes when compared to $\mathrm{PM}$ insulin $\mathrm{BID} \pm \mathrm{OAD}$, indicating that $\mathrm{BA}$ insulin may be the best choice when initiating insulin therapy in T2DM patients. During insulin therapy escalation, BB insulin $1 \times$ did not produce a statistically significant difference in efficacy compared to PM insulin BID, but it did lead to a significant decrease in body weight change. In contrast, BB insulin $3 \times$ therapy produced a statistically significant decrease in HbA1c change and an increased likelihood of achieving HbA1c $\leq 7 \%$ but no statistically significant difference in change from baseline in body weight or likelihood of total hypoglycemia as compared to PM insulin BID. This demonstrates that, despite its complicated injection schedule, BB insulin $3 \times$ would be a more favorable escalation choice for patients with uncontrolled glycemia than the simpler PM insulin BID regimen.

A unique aspect of our systematic literature review and meta-analysis is that we also explored how treatment type and patient characteristics affected the change in HbA1c from baseline and total hypoglycemia. Firstly, when stratified by PM insulin type, BA insulin demonstrated statistically significant improvements in change from baseline HbA1c as compared to regular human PM and a PM ratio of 50/50 (see Table S4 of the ESM). Secondly, BA insulin yielded a statistically significant decrease in the likelihood of total hypoglycemia compared to lispro PM insulin and PM insulin with a ratio of 70/30. Lastly, our analyses revealed that the decrease in total hypoglycemia for BA as compared to PM insulin was significant in non-Asian populations, studies with a follow-up period of $<26$ weeks, as well as patients with a baseline HbA1c of $\geq 9 \%$ (Table S5 in the ESM). No other statistically significant difference was found in these exploratory analyses.

Although this pairwise meta-analysis provides evidence that can be used to address a question that was previously unresolved, there are limitations to this systematic literature review. The pairwise meta-analysis was conducted with a limited number of studies since only those that compared BA insulin directly to PM insulin were considered. Due to the limited number of studies included in the quantitative analysis, full evaluations of the differences in efficacy and safety between BA and PM insulin were difficult to assess. Heterogeneity was significantly ( $p$ value $<0.05$ ) high $(>70 \%)$ in most of the overall analyses due to variations in sample size and effect size. Eight additional subgroup analyses observed high levels of heterogeneity $\left(I^{2}\right.$ values $\left.>70 \%\right)$. Exploratory analyses of PM insulin type, PM insulin ratio, BA insulin type, and ethnicity/race were limited by the number of studies included in each comparison. In addition, there was also a bias due to the overrepresentation of certain categories such as BA insulin type. 
Previous systematic literature reviews and meta-analyses provided inconsistent results regarding the superiority of BA or PM insulin $[7,8]$. A more recent systematic literature review claimed that there was no clinically relevant difference in efficacy and safety outcomes between BB and PM insulin [9]. Our systematic literature review differed in that it included a wider pool of studies, which permitted an exploration of not only the difference between BB and PM insulin but also between $\mathrm{BA}$ and $\mathrm{PM}$ insulin regimens $\pm \mathrm{OAD}$ therapy. Two studies included in the 2016 systematic literature review were excluded from this systematic literature review because they were classified as a pragmatic trial [34] or a substudy [35] instead of a primary RCT. The discussed results could also have been impacted by the range of insulin treatments we considered, and thus the greater number of references that were analyzed.

\section{CONCLUSION}

In conclusion, this systematic literature review and meta-analysis revealed that BA insulin regimens yielded significant improvements in fasting glucose, body weight change, and risk of total hypoglycemia as compared to PM insulin regimens, but further research is needed to confirm these results.

\section{ACKNOWLEDGEMENTS}

Funding. This study and journal processing charges were funded by Sanofi (Shanghai, China). All authors had full access to all of the data in this study and take complete responsibility for the integrity of the data and accuracy of the data analysis.

Medical Writing and Other Assistance. The study was executed and analyzed at Doctor Evidence. Medical writing assistance was conducted by Doctor Evidence and sponsored by Sanofi (Shanghai, China). We thank Angelica Stamegna for her publication support and Lionel Duarte and Gaye Siliman of Doctor Evidence for statistical expertise.
Authorship. All named authors meet the International Committee of Medical Journal Editors (ICMJE) criteria for authorship for this article, take responsibility for the integrity of the work as a whole, and have given their approval for this version to be published.

Disclosures. Nan Cui is an employee of Sanofi, China. Yunguang Li is an employee of Sanofi, China. Ambar Grijalva reports employment by Doctor Evidence, who was contracted to produce the analysis. Erin Murray reports employment by Doctor Evidence, who was contracted to produce the analysis. Michael del Aguila reports employment by Doctor Evidence, who was contracted to produce the analysis. Ting Hong, Jing Lu, Pengzi Zhang, Zhou Zhang, Qianyue $\mathrm{Xu}$, and $\mathrm{Bi}$ Yan have nothing to disclose.

Compliance with Ethics Guidelines. This article is based on previously conducted studies and does not contain any studies with human participants or animals performed by any of the authors.

Data Availability. The datasets obtained during and/or analyzed during the current study are available from the corresponding author on reasonable request.

Open Access. This article is distributed under the terms of the Creative Commons Attribution-NonCommercial 4.0 International License (http://creativecommons.org/licenses/ by-nc/4.0/), which permits any noncommercial use, distribution, and reproduction in any medium, provided you give appropriate credit to the original author(s) and the source, provide a link to the Creative Commons license, and indicate if changes were made.

\section{REFERENCES}

1. World Health Organization. Global report on diabetes 2016. Geneva: World Health Organization; 2016. 
2. Tinahones FJ, Gross JL, Onaca A, Cleall S, Rodríguez A. Insulin lispro low mixture twice daily versus basal insulin glargine once daily and prandial insulin lispro once daily in patients with type 2 diabetes requiring insulin intensification: a randomized phase IV trial. Diabetes Obes Metab. 2014;16(10):963-70.

3. Weng J, Ji L, Jia W, Lu J, Zhou Z, Zou D, et al. Standards of care for type 2 diabetes in China. Diabetes Metab Res Rev. 2016;32(5):442-58.

4. Inzucchi SE, Bergenstal RM, Buse JB, Diamant M, Ferrannini E, Nauck $M$, et al. Management of hyperglycemia in type 2 diabetes, 2015: a patientcentered approach: update to a position statement of the American Diabetes Association and the European Association for the Study of Diabetes. Diabetes Care. 2015;38(1):140-9.

5. Cahn A, Miccoli R, Dardano A, Del Prato S. New forms of insulin and insulin therapies for the treatment of type 2 diabetes. Lancet Diabetes Endocrinol. 2015;3(8):638-52.

6. Bellido V, Suarez L, Rodriguez MG, Sanchez C, Dieguez M, Riestra M, et al. Comparison of basalbolus and premixed insulin regimens in hospitalized patients with type 2 diabetes. Diabetes Care. 2015;38(12):2211-6.

7. Giugliano D, Maiorino MI, Bellastella G, Chiodini P, Ceriello A, Esposito K. Efficacy of insulin analogs in achieving the hemoglobin A1c target of $<7 \%$ in type 2 diabetes: meta-analysis of randomized controlled trials. Diabetes Care. 2011;34(2):510-7.

8. Esposito K, Maiorino MI, Bellastella G, Chiodini P, Giugliano D. Insulin analogs and glycosylated hemoglobin target of less than 7\% in type 2 diabetes: a systematic review of randomized trials. Metab Syndr Relat Disord. 2011;9(3):167-76.

9. Giugliano D, Chiodini P, Maiorino MI, Bellastella $\mathrm{G}$, Esposito K. Intensification of insulin therapy with basal-bolus or premixed insulin regimens in type 2 diabetes: a systematic review and metaanalysis of randomized controlled trials. Endocrine. 2016;51(3):417-28.

10. Higgins JPT, Green S, Cochrane Collaboration. Cochrane handbook for systematic reviews of interventions. Chichester: Wiley; 2008.

11. Higgins JPT, Altman DG, Gøtzsche PC, et al. The Cochrane Collaboration's tool for assessing risk of bias in randomised trials. BMJ. 2011;343:d5928.

12. Viechtbauer $\mathrm{W}$. Conducting meta-analyses in $\mathrm{R}$ with the metafor package. J Stat Softw. 2010;36(3):1-48.
13. Al-Shaikh AR. Comparison of basal insulin added to oral agents versus twice-daily premixed insulin as initial insulin therapy for type 2 diabetes. Pak J Med Sci. 2006;22(1):14-7.

14. Buse JB, Wolffenbuttel BH, Herman WH, Shemonsky NK, Jiang HH, Fahrbach JL, et al. DURAbility of basal versus lispro mix 75/25 insulin efficacy (DURABLE) trial 24-week results: safety and efficacy of insulin lispro mix 75/25 versus insulin glargine added to oral antihyperglycemic drugs in patients with type 2 diabetes. Diabetes Care. 2009;32(6): 1007-13.

15. Cao Y, Gao F, Zhang Q, Xu L, Wan Q, Li W, et al. Efficacy and safety of co-administration of sitagliptin with insulin glargine in type 2 diabetes. J Diabetes. 2017;9(5):502-9.

16. Holman RR, Farmer AJ, Davies MJ, Levy JC, Darbyshire JL, Keenan JF, et al. Three-year efficacy of complex insulin regimens in type 2 diabetes. $\mathrm{N}$ Engl J Med. 2009;361(18):1736-47.

17. Janka HU, Plewe G, Riddle MC, Kliebe-Frisch C, Schweitzer MA, Yki-Järvinen H. Comparison of basal insulin added to oral agents versus twice-daily premixed insulin as initial insulin therapy for type 2 diabetes. Diabetes Care. 2005;28(2):254-9.

18. Kann PH, Wascher T, Zackova V, Moeller J, Medding J, Szocs A, et al. Starting insulin therapy in type 2 diabetes: twice-daily biphasic insulin aspart 30 plus metformin versus once-daily insulin glargine plus glimepiride. Exp Clin Endocrinol Diabetes. 2006;114(9):527-32.

19. Ligthelm RJ, Gylvin T, DeLuzio T, Raskin P. A comparison of twice-daily biphasic insulin aspart $70 / 30$ and once-daily insulin glargine in people with type 2 diabetes inadequately controlled on basal insulin and oral therapy: a randomized openlabel study. Endocr Pract. 2011;17(1):41-50.

20. Raskin P, Allen E, Hollander P, Lewin A, Gabbay RA, $\mathrm{Hu} \mathrm{P}$, et al. Initiating insulin therapy in type 2 diabetes: a comparison of biphasic and basal insulin analogs. Diabetes Care. 2005;28(2):260-5.

21. Zhou J, Zheng F, Guo X, Yang H, Zhang M, Tian H, et al. Glargine insulin/gliclazide MR combination therapy is more effective than premixed insulin monotherapy in Chinese patients with type 2 diabetes inadequately controlled on oral antidiabetic drugs. Diabetes Metab Res Rev. 2015;31(7):725-33.

22. Riddle MC, Rosenstock J, Vlajnic A, Gao L. Randomized, 1-year comparison of three ways to initiate and advance insulin for type 2 diabetes: twicedaily premixed insulin versus basal insulin with either basal-plus one prandial insulin or basal-bolus 
up to three prandial injections. Diabetes Obes Metab. 2014;16(5):396-402.

23. Vora J, Cohen N, Evans M, Hockey A, Speight J, Whately-Smith $\mathrm{C}$. Intensifying insulin regimen after basal insulin optimisation in adults with type 2 diabetes: a 24-week, randomised, open-label trial comparing insulin glargine plus insulin glulisine and biphasic insulin aspart (LanScape). Diabetes Obes Metab. 2015;17(12):1133-41.

24. Fritsche A, Larbig M, Owens D, Häring HU. Comparison between a basal-bolus and a premixed insulin regimen in individuals with type 2 diabetes-results of the GINGER study. Diabetes Obes Metab. 2010;12(2):115-23.

25. Liebl A, Prager R, Binz K, Kaiser M, Bergenstal R, Gallwitz B. Comparison of insulin analogue regimens in people with type 2 diabetes mellitus in the PREFER study: a randomized controlled trial. Diabetes Obes Metab. 2009;11(1):45-52.

26. Jia W, Xiao X, Ji Q, Ahn KJ, Chuang LM, Bao Y, et al. Comparison of thrice-daily premixed insulin (insulin lispro premix) with basal-bolus (insulin glargine oncedaily plus thrice-daily prandial insulin lispro) therapy in east Asian patients with type 2 diabetes insufficiently controlled with twice-daily premixed insulin: an open-label, randomised, controlled trial. Lancet Diabetes Endocrinol. 2015;3(4):254-62.

27. Rosenstock J, Ahmann AJ, Colon G, Scism-Bacon J, Jiang H, Martin S. Advancing insulin therapy in type 2 diabetes previously treated with glargine plus oral agents: prandial premixed (insulin lispro protamine suspension/lispro) versus basal/bolus (glargine/lispro) therapy. Diabetes Care. 2008;31(1):20-5.

28. Bowering K, Reed VA, Felicio JS, Felicio J, Landry J, Ji L, et al. A study comparing insulin lispro mix 25 with glargine plus lispro therapy in patients with type 2 diabetes who have inadequate glycaemic control on oral anti-hyperglycaemic medication: results of the PARADIGM study. Diabet Med. 2012;29(9):e263-72.

29. Giugliano D, Tracz M, Shah S, Calle-Pascual A, Mistodie C, Duarte R, et al. Initiation and gradual intensification of premixed insulin lispro therapy vs. basal $\{ \pm\}$ mealtime insulin in patients with type 2 diabetes eating light breakfasts. Diabetes Care. 2014;37(2):372-80.

30. Jain SM, Mao X, Escalante-Pulido M, Vorokhobina N, Lopez I, Ilag LL. Prandial-basal insulin regimens plus oral antihyperglycaemic agents to improve mealtime glycaemia: initiate and progressively advance insulin therapy in type 2 diabetes. Diabetes Obes Metab. 2010;12(11):967-75.

31. Jin SM, Kim JH, Min KW, Lee JH, Ahn KJ, Park JH, et al. Basal-prandial versus premixed insulin in patients with type 2 diabetes requiring insulin intensification after basal insulin optimization: a 24-week randomized non-inferiority trial. J Diabetes. 2016;8(3):405-13.

32. Linjawi S, Lee BW, Tabak Ö, Lövdahl S, Werther S, Abusnana S. A 32-week randomized comparison of stepwise insulin intensification of biphasic insulin aspart (BIAsp 30) versus basal-bolus therapy in insulin-naïve patients with type 2 diabetes. Diabetes Ther. 2018;9(1):1-11.

33. Malek R, Ajili F, Assaad-Khalil SH, Shinde A, Chen JW, Van den Berg E. Similar glucose control with basalbolus regimen of insulin detemir plus insulin aspart and thrice-daily biphasic insulin aspart 30 in insulinnaive patients with type 2 diabetes: results of a 50-week randomized clinical trial of stepwise insulin intensification. Diabetes Metab. 2015;41(3):223-30.

34. Levin PA, Zhang Q, Mersey JH, Lee FY, Bromberger LA, Bhushan M, et al. Glycemic control with insulin glargine plus insulin glulisine versus premixed insulin analogues in real-world practices: a cost-effectiveness study with a randomized pragmatic trial design. Clin Ther. 2011;33(7):841-50.

35. Miser WF, Arakaki R, Jiang H, Scism-Bacon J, Anderson PW, Fahrbach JL. Randomized, open-label, parallel-group evaluations of basal-bolus therapy versus insulin lispro premixed therapy in patients with type 2 diabetes mellitus failing to achieve control with starter insulin treatment and continuing oral antihyperglycemic drugs: a noninferiority intensification substudy of the DURABLE trial. Clin Ther. 2010;32(5):896-908. 